\title{
Clinical and Molecular Spectrum of Four Patients Diagnosed with Mowat-Wilson Syndrome
}

\author{
Durdugul Ayyildiz Emecen ${ }^{\mathrm{a}}$ Esra Isik $^{\mathrm{a}} \quad$ Gulen E. Utine $^{\mathrm{b}}$ Pelin O. Simsek-Kiper ${ }^{\mathrm{b}}$ \\ Tahir Atik $^{\mathrm{a}}$ Ferda Ozkinay ${ }^{\mathrm{a}}$ \\ aDivision of Pediatric Genetics, Department of Pediatrics, Faculty of Medicine, Ege University, Izmir, Turkey; ${ }^{\mathrm{b}}$ Division \\ of Pediatric Genetics, Department of Pediatrics, Faculty of Medicine, Hacettepe University, Ankara, Turkey
}

\section{Keywords}

Facial dysmorphism - Genetic syndrome - Language

impairment $\cdot$ Mowat-Wilson syndrome $\cdot$ ZEB2

\begin{abstract}
Mowat-Wilson syndrome (MWS) is a rare autosomal dominant syndrome characterized by distinctive facial features, congenital heart defects, Hirschsprung disease, genitourinary anomalies, various structural brain anomalies, and intellectual disability. Pathogenic mutations that result in haploinsufficiency in the ZEB2 gene cause MWS. In this study, we aimed to evaluate the clinical features and molecular analysis results of 4 MWS patients. All patients were examined by an expert clinical geneticist. Dysmorphological abnormalities were recorded. Data including demographic, clinical, and laboratory findings were obtained from hospital records. ZEB2 gene analysis was performed using a Sanger sequencing method. All patients had typical facial features of MWS such as widely spaced eyes, broad eyebrows with a medial flare, low-hanging columella, prominent or pointed chin, open-mouth expression, and uplifted earlobes. Four different heterozygous mutations were identified; 2 mutations were frameshift (c.246_247delGGinsC, c.980_980delG),
\end{abstract}

1 was nonsense (c.2083C >T), and 1 was splice site (c.808$2 A>G$ ). Two of them (c.246_247delGGinsC, c.980_980delG) have not been previously reported in the literature. By defining 2 novel mutations, this study contributes to the molecular spectrum of MWS, while also providing a further insight for genetic counseling. It also demonstrates the importance of dysmorphological examination in clinical diagnosis.

(c) 2020 S. Karger AG, Base

\section{Introduction}

Mowat-Wilson syndrome (MWS) is a single gene disorder characterized by dysmorphic facial features, congenital heart defects, Hirschsprung disease (HSCR), genitourinary anomalies, corpus callosum hypo/agenesis, and intellectual disability [Ivanovski et al., 2018]. The most characteristic facial features are widely spaced eyes, broad eyebrows with a medial flare, low-hanging columella, prominent or pointed chin, open-mouth expression, and uplifted earlobes with a central depression [Adam et al., 2019]. Most of the affected individuals have moderate to severe intellectual disability. In addition, microcephaly, epilepsy, and growth retardation

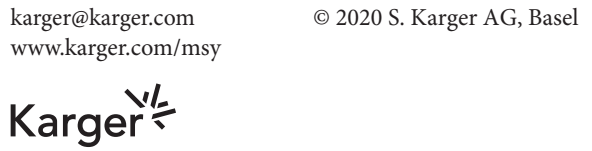

Durdugul Ayyildiz Emecen

Division of Pediatric Genetics,Department of Pediatrics,Faculty of Medicine/Ege University Genclik Street

Izmir 35100 (Turkey)

ayyildizdurdugul@gmail.com 
Table 1. The clinical findings of the patients

\begin{tabular}{|c|c|c|c|c|c|c|}
\hline & Patient-1 & Patient-2 & Patient-3 & Patient-4 & This study & Literature \\
\hline Age & 4 ys & 13 ys & 5 ys & 5 ys & & \\
\hline Weight* & $25 \mathrm{P}$ & $25-50 \mathrm{P}$ & $75-95 \mathrm{P}$ & $5 \mathrm{P}$ & & \\
\hline Height* & $5-25 \mathrm{P}$ & $75-95 \mathrm{P}$ & $25-50 \mathrm{P}$ & $25 \mathrm{P}$ & & \\
\hline Sitting age & $1 \mathrm{y}$ & 4 ys & $1.5 \mathrm{ys}$ & $1 \mathrm{y}$ & & \\
\hline Independent walking & $5.5 \mathrm{ys}$ & 4 ys & $2.5 \mathrm{ys}$ & $5 \mathrm{ys}$ & & \\
\hline First words & 5 ys & 5 ys & 3 ys & 4 ys & & \\
\hline Decreased pain sensitivity & - & + & - & - & & \\
\hline Facial gestalt & + & + & + & + & $4 / 4(100 \%)$ & $>90 \% * *$ \\
\hline Microcephaly & + & + & + & + & $4 / 4(100 \%)$ & $78 \% * *$ \\
\hline Seizures & + & + & + & + & $4 / 4(100 \%)$ & $79 \% * *$ \\
\hline Cranial MRI & $\begin{array}{l}\text { Myelination } \\
\text { defect }\end{array}$ & $\begin{array}{l}\text { Millimetric gliotic area in } \\
\text { periventricular white matter }\end{array}$ & $\begin{array}{l}\text { Incomplete hippocampal } \\
\text { inversion }\end{array}$ & $\begin{array}{l}\text { MRI was not } \\
\text { available }\end{array}$ & & $94 \% * * *$ \\
\hline Congenital heart defect & - & + & + & - & $2 / 4(50 \%)$ & $58 \% * *$ \\
\hline Hirschsprung disease & - & - & - & + & $1 / 4(25 \%)$ & $44 \%^{* *}$ \\
\hline Constipation & - & - & - & + & $1 / 4(25 \%)$ & $29 \% * *$ \\
\hline
\end{tabular}

ys, years. * Growth parameters, according to the MWS growth chart; ** Adam et al. [2019]; *** Garavelli et al. [2017]

can be observed. The patients generally have a happy demeanor and a wide-based gait, which sometimes can be confused with Angelman syndrome [Adam et al., 2019]. Heterozygous single nucleotide mutations resulting in haploinsufficiency in the zinc finger E boxbinding homeobox 2 (ZEB2) gene are responsible for approximately $80 \%$ of the patients. Large intragenic deletions/duplications and large rearrangements detectable by fluorescence in situ hybridization are reported in $15 \%$, while partial gene deletions of single exons detectable by quantitative PCR, multiplex ligation-dependent probe amplification, or array-based comparative genomic hybridization reported in $5 \%$ of the affected individuals [Saunders et al., 2009]. In this study, we aimed to evaluate the clinical features and molecular analysis results of 4 MWS patients.

\section{Materials and Methods}

This study included 4 unrelated MWS patients referred to the Pediatric Genetics Department due to dysmorphic features and developmental delay. All patients were examined by a clinical geneticist and clinical MWS diagnosis was established depending on dysmorphological features. Data including demographic, clinical, and laboratory findings were obtained from hospital records. The latest growth parameters of the patients were measured and evaluated according to the growth curves for MWS designed by Ivanovski et al. [2020].

\section{Molecular Analysis}

Genomic DNA was isolated from peripheral blood with $2 \mathrm{cc}$ EDTA using the QIAamp DNA Blood Mini Kit (Qiagen Ltd, Crawley, UK). Appropriate primers were designed to amplify all coding exonic regions (exons 2-10) and exon-intron junctions of the ZEB2 gene. Amplicons formed by amplifying the target region by polymerase chain reaction (PCR) were sequenced by the Sanger method on the ABI 3130 analyzer following the control and puri- 
Fig. 1. Dysmorphological findings of the patients. Please note: uplifted earlobes, sparse eyebrows with medial flaring, prominent columella, and an open-mouth expression. a Patient 1. b Patient 2. c Patient 3. d Patient 4.
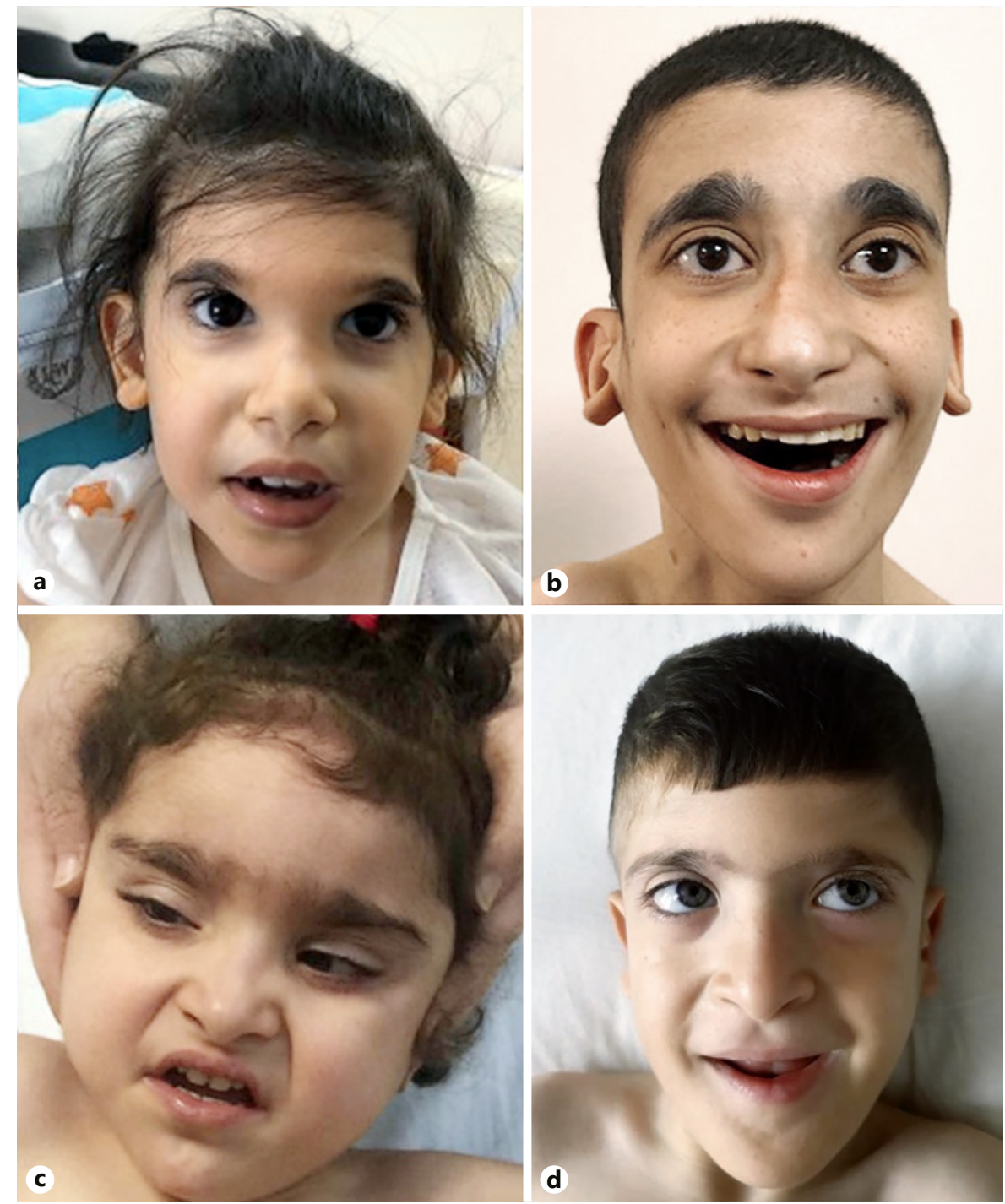

fication steps. Pathogenicity of novel mutations was classified in accordance with the American College of Medical Genetics (ACMG-2015) guidelines.

\section{Results}

Our study included 4 patients diagnosed to have MWS from 4 different families. Two patients were females and 2 were males. None of the parents were consanguineous. The mean age of the patients was 6 years and 9 months. All patients were referred to the Pediatric Genetics Department due to the neurodevelopmental delay starting in early childhood. They all were born at term with normal weight and height. On hospital admission, microcephaly was detected in all patients and postnatal short stature in
2 of them (Patients 1 and 4); however, their weight, height, and head circumferences were found to be in normal ranges according to the MWS growth curves (Table 1).

On dysmorphological examination, all patients had the typical facial features of MWS: uplifted earlobes, sparse eyebrows with medial flaring, prominent columella, and an open-mouth expression (Fig. 1). They all had neurodevelopmental delay and epilepsy. Different seizure types including focal motor, generalized tonic, and generalized tonic-clonic were observed (Table 1). Their speech skills were well behind compared to the other motor milestones. None of the patients were able to construct a sentence, and the mean age for their first word was 4 years. The average age of walking independently was 4 years 3 months. All patients had a cheerful and social personality. A history of decreased pain sensitivity was observed only in Patient 2. 
Table 2. Molecular findings of the patients

\begin{tabular}{lllllll}
\hline $\begin{array}{l}\text { Patient } \\
\text { no }\end{array}$ & cDNA & Protein & $\begin{array}{l}\text { Exon/ } \\
\text { Intron }\end{array}$ & $\begin{array}{l}\text { Mutation } \\
\text { type }\end{array}$ & Pathogenicity & Novelty \\
\hline $\mathbf{1}$ & c.808-2A>G & - & Intron 6 & S & $\mathrm{P}$ & Known \\
2 & c.246_247delGGinsC & p.Glu82AspfsTer7 & Exon 3 & FS & $\mathrm{P}$ & Novel \\
3 & c.2083C $>$ T & p.Arg695* & Exon 8 & NS & P & Known \\
4 & c.980_980delG & p.Gly351f* & Exon 8 & FS & P & Novel \\
\hline
\end{tabular}

FS, frameshift; NS, nonsense; $\mathrm{P}$, pathogenic; S, splice site.

Cranial MRI was available in 3 patients. Their cranial MRI features are shown in Table 1.

HSCR disease was observed and operated on in only one patient (Patient 4). No history of constipation was observed in the other 3 patients. Two patients (Patient 2 and 3 ) had patent ductus arteriosus and ligation was performed in the neonatal period. Their latest echocardiographic examinations showed pulmonary stenosis in Patient 2 , atrial septal defect, muscular ventricular septal defect, and pulmonary stenosis in Patient 3. Ocular examination revealed congenital coloboma in Patient 1, strabismus in Patient 3, and posterior embryotoxon in Patient 4. Patient 1 was operated on due to trigonocephaly. Patient 4 had brachycephaly. Bone $\mathrm{X}$-ray revealed an enlargement of the proximal phalanx joints in Patient 2. Both male patients were operated on for cryptorchidism. No urogenital anomalies were detected in the 2 female patients. The clinical findings of the patients are shown in Table 1.

\section{Molecular Results}

Four different mutations in the ZEB2 gene were detected in 4 patients. Two of the mutations (c.246_247delGGinsC, c.980_980delG) have not been previously reported in the literature. All mutations were de novo. Two mutations were frameshift (c.246_247delGGinsC, c.980_980delG), one nonsense (c.2083C>T), and one splice site (c.808-2A>G). The molecular analysis results of the patients are shown in Table 2.

\section{Discussion}

MWS is a rare genetic syndrome characterized by intellectual disability and dysmorphological features. More than 300 patients have been reported to date [Cooper et al., 2017]. It is caused by ZEB2 haploinsufficieny. Characteristic facial features provide the first clue to recognize the syndrome. Facial gestalt becomes more distinctive as the child grows older; however, it is recognizable also in early childhood. In our study, the youngest patient was 5 years old, and all had the characteristic facial features of MWS described in the literature, such as uplifted earlobes, sparse eyebrows with medial flaring, prominent columella, and an open-mouth expression [Garavelli et al., 2009; Ivanovski et al., 2018; Ho et al., 2020].

Recent studies showed that MWS affects males and females equally [Ivanovski et al., 2018]. MWS causes postnatal growth retardation. The birth weight and length of patients are in the normal range; however, microcephaly can be present at birth [Adam et al., 2019]. In our study, all patients had normal weight and height at birth. Their head circumferences were not recorded at birth, but all presented with severe microcephaly on their latest examinations, when compared to healthy individuals. A previous study showed that short stature typically develops over time. In agreement with this, 2 of our patients were diagnosed with short stature. However, recently, Ivanovski et al. [2020] designed a specific growth chart for MWS patients. Following this publication, we reevaluated the growth parameters of the patients and observed that all were in the normal range according to the growth curves designed for MWS patients. Neurodevelopmental milestones are generally delayed in MWS. Mean age of independent walking is 4 years. Speech delay is typical and the majority of patients had either absent or severely restricted speech [Adam et al., 2019]. In accordance with the previous reports, the mean walking age was 4 years 3 months in our study, and all patients could speak only 1 or 2 words [Adam et al., 2019].

In MWS, structural brain anomalies are also common and can be detected on cranial MRI. Garavelli et al. [2017] showed that $94 \%$ of the MWS patients had abnormal cranial MRI results. In their series of 54 MWS patients, the corpus callosum abnormalities (79.6\%), hippocampal abnormalities (77.8\%), and enlargement of cerebral ventricles $(68.5 \%)$ were the most common structural brain 
anomalies [Garavelli et al., 2017]. In our study, abnormal cranial MRI results were detected in 3 patients. In none of them corpus callosum abnormalities were observed. However, 2 had white matter abnormalities, and 1 had hippocampal inversion as shown in Table 1.

Seizures are one of the most common neurological findings present in $80 \%$ of the MWS patients [Cordelli et al., 2013]. In a study from Turkey, epileptic seizures were described in 4 of 6 MWS patients [Kilic et al., 2016]. In our study, all patients were diagnosed to have epilepsy. Multiple types of seizures - focal and generalized - were observed in all patients. Behavior abnormalities, especially a happy demeanor with frequent laughter, are also common when compared to individuals with moderateto-severe cognitive impairment caused by other genetic syndromes [Evans et al., 2012]. In our study, all 4 patients were noted with a happy demeanor and social personality. Underreaction to pain has also been described in MWS patients. Ivanovski et al. [2018] reported decreased pain sensitivity in more then $60 \%$ of their study population. However, in our study only one patient showed decreased pain sensitivity.

HSCR disease is one of the most characteristic features of MWS. The HSCR rate was reported to be $44 \%$ in a previous study [Adams et al., 2019]. However, recent studies have shown that the rate of HSCR is decreasing with the number of diagnosed MWS patients increasing [Coyle and Puri, 2015]. This was attributed to the fact that MWS diagnosis is based on facial features rather than the presence of HSCR [Ivanovski et al., 2018], and among those patients with HSCR, MWS could be diagnosed earlier than facial recognition in later years.

Another common feature of MWS are congenital cardiac anomalies, with a rate of 58\% [Adam et al., 2019]. In our study, 2 patients had patent ductus ateriosus, atrial septal defect or ventricular septal defect as cardiac malformations. Skeletal and ocular anomalies can also be detected in MWS [Adam et al., 2019]. In our study, 3 patients (75\%) had both skeletal and ocular findings. Genital anomalies, such as cryptorchidism and hypospadias, are found in $60 \%$ of males with MWS [Adam et al., 2019]. Our group included 2 male patients, and both had cryptorchidism.

Monoallelic mutations in the ZEB2 gene are responsible for MWS. The ZEB2 gene encodes the Sip1 protein which plays roles in the regulation of many steps in embryogenesis. ZEB2 is also highly evolutionarily conserved, which means that even small changes may result in a protein dysfunction [Dastot-Le Moal et al., 2007]. To date, more than 200 mutations, including 87 small deletions, 65 missense/nonsense mutations, have been reported in the ZEB2 gene [Cooper et al., 2017]. Defects in exon 8 constitute $50 \%$ of all defects in the ZEB2 gene [Saunders et al., 2009]. Most of the ZEB2 variants defined in MWS patients are whole-gene deletions or intragenic truncating mutations as in our patients. This indicates that haploinsufficiency is the underlying mechanism of MWS [Dastot-Le Moal et al., 2007].

In our study, we defined 4 different $Z E B 2$ mutations. All were proved to be de novo by family segregation analyses. Two of them were frameshift, 1 nonsense, and 1 splice site. Consistent with the literature, $50 \%$ of the mutations detected in our patients were in exon 8 . Besides, 2 of the 4 mutations were not reported in the literature previously. Novel mutations are important to enlarge the molecular spectrum of genetic syndromes and to possibly understand the genotype-phenotype correlation in larger patient groups.

\section{Conclusion}

By defining 2 novel mutations, this study contributes to the molecular spectrum of MWS, while also providing a further insight for genetic counseling. It also demonstrates the value of clinical diagnosis in light of dysmorphic evaluations, in terms of time, money and resources.

\section{Statement of Ethics}

Samples from the patients were obtained in accordance with the Helsinki Declarations. Written informed consent for genetic testing was obtained from all patients and/or their parents/guardians.

\section{Conflict of Interest Statement}

All authors declare that they have no conflict of interest.

\section{Funding Sources}

None.

\section{Author Contributions}

Project design: D.A.E., E.I., T.A., and F.O. Data collection and clinical evaluation: D.A.E., and E.I. Sequence analysis: G.E.U. and P.O.S.K. Preparation of the manuscript: D.A.E., E.I., T.A., and F.O. All authors read and approved the manuscript. 


\section{References}

Adam MP, Conta J, Bean LJH: Mowat-Wilson syndrome. In: Pagon RA, Adam MP, Ardinger HH, Wallace SE, Amemiya A, Bean LJH, et al (eds): GeneReviews ${ }^{\oplus}$ [Internet] (University of Washington, Seattle 1993-2020). Initial posting: March 28, 2007; last update: July 25, 2019.

Cooper DN, Ball EV, Stenson PD, Phillips AD, Evans $\mathrm{K}$, Heywood S, et al. Human Gene $\mathrm{Mu}-$ tation Database (HGMD). Human Mutat. 2017;21(6):577-81.

Cordelli DM, Garavelli L, Savasta S, Guerra A, Pellicciari A, Giordano L, et al. Epilepsy in Mowat-Wilson syndrome: Delineation of the electroclinical phenotype Am J Med Genet A. 2013;161A:273-84.

Coyle D, Puri P. Hirschsprung's disease in children with Mowat-Wilson syndrome. Pediatr Surg Int. 2015;31(8):711-7.
Dastot-Le Moal F, Wilson M, Mowat D, Collot N, Niel F, Goossens M. ZFHX1B mutations in patients with Mowat-Wilson syndrome. Hum Mutat 2007;28:313-21 ().

Evans E, Einfeld S, Mowat D, Taffe J, Tonge B, Wilson M. The behavioral phenotype of Mowat-Wilson syndrome. Am J Med Genet A. 2012;158A(2):358-66.

Garavelli L, Zollino M, Mainardi PC, Gurrieri F, Rivieri F, Soli F, et al. Mowat-Wilson syndrome: facial phenotype changing with age: study of 19 Italian patients and review of the literature. Am J Med Genet A. 2009;149A: 417-26.

Garavelli L, Ivanovski I, Caraffi SG, Santodirocco D, Pollazzon M, Cordelli D, et al. Neuroimaging findings in Mowat-Wilson syndrome: a study of 54 patients. Genet Med. 2017;19: 691-700.

Ho S, Luk HM, Chung BHY, Fung JLF, Mak HHY, Lo IF. Mowat-Wilson syndrome in a Chinese population: A case series. Am J Med Genet A. 2020;182:1336-41.
Ivanovski I, Djuric O, Caraffi SG, Santodirocco D, Pollazzon M, Rosato S, et al. Phenotype and genotype of 87 patients with Mowat-Wilson syndrome and recommendations for care. Genet Med. 2018;20(9):965-75.

Ivanovski I, Djuric O, Broccoli S, Caraffi SG, Accorsi P, Adam MP, et al. Mowat-Wilson Syndrome: Growth Charts. Orphanet J Rare Dis. 2020;15(1):151.

Kilic E, Cetinkaya A, Utine E, Boduroglu K. A Diagnosis to Consider in Intellectual Disability: Mowat-Wilson Syndrome. J Child Neurol. 2016; 31(7): 913-17. http: //dx.doi. org/10.1177/0883073815627884.

Saunders CJ, Zhao W, Ardinger HH. Comprehensive ZEB2 gene analysis for Mowat-Wilson syndrome in a North American cohort: a suggested approach to molecular diagnostics. Am J Med Genet A. 2009;149A:2527-31. 